\title{
A NEW TOOL BASED ON FAECAL STANOLS CAN DISTINGUISH SPECIFIC MAMMALIAN SPECIES IN MODERN AND PAST ENVIRONMENTS
}

\author{
L. Harrault ${ }^{1,2,3}$, K. Milek ${ }^{2,3}$, E. Jardé ${ }^{4}$, L. Jeanneau ${ }^{4}$, M. Derrien ${ }^{5}$, R. Bindler ${ }^{6}$, J. Klaminder 6 , \\ D. G. Anderson ${ }^{3}$
}

${ }^{1}$ Sorbonne Université, France, ${ }^{2}$ Durham University, UK, ${ }^{3}$ University of Aberdeen, UK, ${ }^{4}$ Université Rennes, France, ${ }^{5}$ Sejong University, South Korea, ${ }^{6}$ Umeå University, Sweden

Tracking the origin of faecal material in modern and past environments is of primary importance as it can help archaeologists and paleoecologists identifying animal activity areas for example [1]. For the past few decades, sterol-derived compounds have been used as faecal biomarkers to identify the main sources of faecal inputs in different environments, and especially to distinguish a human/omnivore origin from a herbivore one [2]. Simple compound ratios of a limited number of these biomarkers have been used as source identification proxies, but these ratios have limited ability to distinguish the origin of faecal material at the species level, especially among herbivore species [3]. Here, we focused on the analysis of $5 \beta$-stanols, direct faecal biomarkers, from the faeces of ten mammal species to create a faecal fingerprint database. In combination with multivariate analysis, the applicability of this database to distinguish faecal signatures in soil samples at the species level was tested on different modern and archaeological studies to validate its usefulness as a faecal source proxy.

Based on the analysis of $115 \beta$-stanols in 90 modern faeces samples from mammals, we were able to build a faecal signature database allowing the distinction not only at the diet level (omnivore versus herbivores) but also at the species level within each diet group with different degrees of specificity (Figure 1) [4].

This database was tested on a modern camp site from southern Siberia where horses and reindeer have been marshalled seasonally for a few decades, and still are today. The faecal signature of soil samples collected at the site revealed either horse or reindeer signatures, confirming the potential of our tool to identify the main species origin of faecal material in soil.

Our database was also used to confirm hypotheses from different archaeological contexts:

- on a $5^{\text {th }}-12^{\text {th }}$ century AD site from the Iamal Peninsula in Russia thought to have been an early site of reindeer domestication, soil sample faecal signatures confirmed this hypothesis and also confirmed the presence of dogs as herding companions;

- in a northern Swedish watershed, the analysis of $5 \beta$-stanols from a lake sediment core confirmed the hypothesis of a continuous past occupation of the area by wild and domesticated reindeer;

- in a Viking-Age house in Reykjavik, we were able to identify a goat faecal signature in a soil sample in a stable area, where soil micromorphology had been unable to distinguish goat from sheep dung; and

- at Hedeby, a Viking-Age town in northern Germany, we were able to identify the presence of cattle in an area identified using soil micromorphology as a stable.

On two of these sites, the species identifications obtained with our model where compared to and in disagreement with the traditional ratio diagnostic method. 


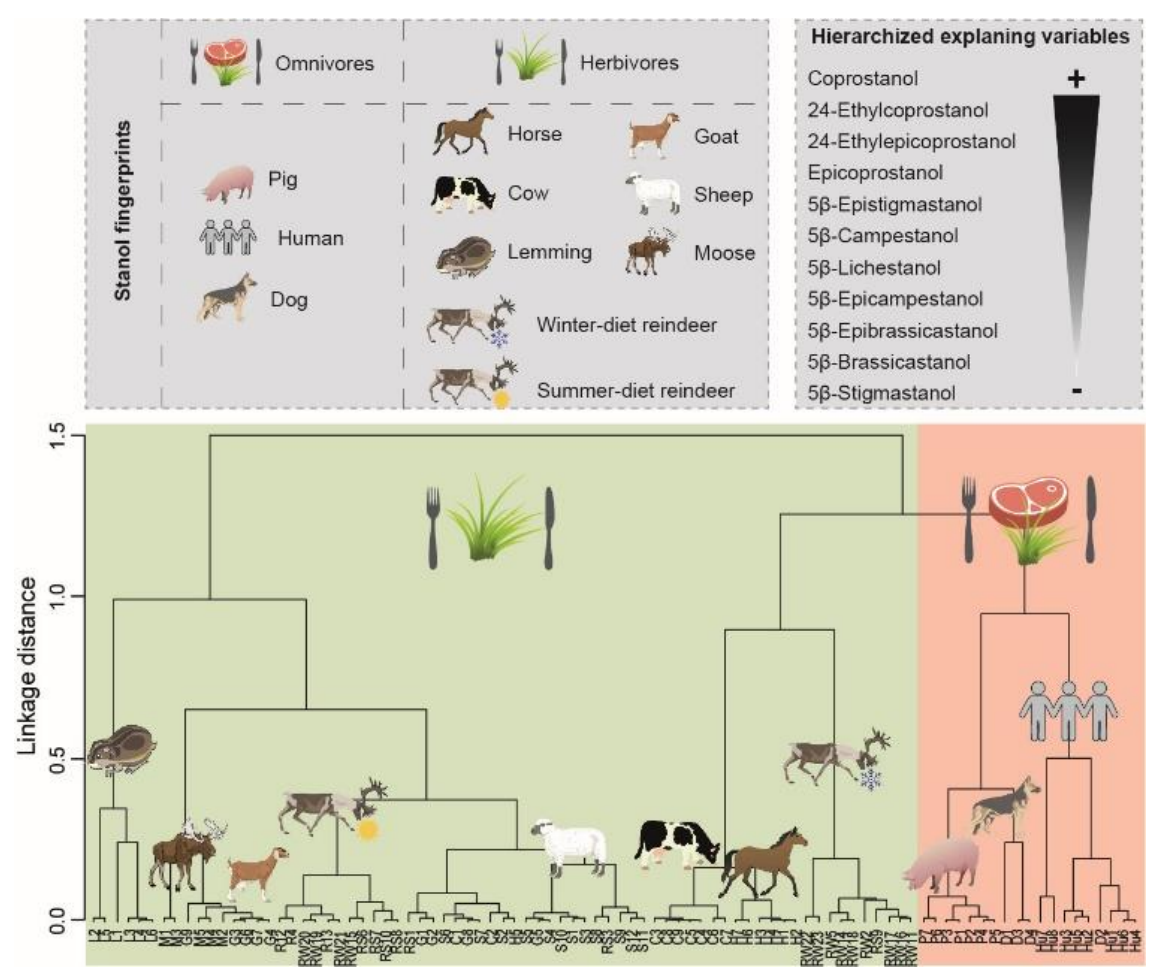

Figure 1 Dendrogram showing the hierarchical cluster analysis of 5 $\beta$-stanol composition of faeces from ten mammal species. The weight of the compounds allowing this distinction is sorted from the more important (+) to the less important (-).

The 5 3 -stanol-based tool developed here allows the identification of species-specific faecal signatures in modern and ancient samples. This new approach overcomes the limitation of previous methods that uses compound ratios based on a limited number of faecal biomarkers. Our faecal fingerprint database model successfully confirmed the main species origin of faecal material inputs in modern and archaeological sites and greatly refined the archaeological interpretations. This database and its ongoing development has important applications not only in archaeology, but also in wathershed management, paleoecology, geochemistry and forensic soil science.

[1] Evershed, R. P. \& Bethell, P. H. (1996). https://doi.org/10.1021/bk-1996-0625.ch013

[2] Bull, I. D., et al. (2002). https://doi.org/10.1016/S0160-4120(01)00124-6

[3] Derrien, M., et al. (2011). https://doi.org/10.1021/jf201040v

[4] Harrault, L., et al. (2019). DOI : 10.1371/journal.pone.0211119 